\title{
INFLUENCE OF HETEROPLASMY ON MOTILITY AND VIABILITY OF BUFFALO AND ZEBU BULL SPERMATOZOA IN UNDILUTED SEMEN
}

\author{
N. N. BORA AND M. BHIMASENA RAO \\ National Dairy Research Institute, Bangalore 560030, India
}

(Received 3rd December 1973)

\begin{abstract}
Summary. The influence of heteroplasmy on sperm viability and motility in the undiluted semen of two buffalo (Bubalus bubalis) breeds and a Zebu cattle breed (Bos indicus) was studied. In undiluted semen stored at $5 \pm 1^{\circ} \mathrm{C}$, Zebu bull semen showed poor keeping quality (av. $32.4 \mathrm{hr}$ ) compared to Murrah (av. $49.7 \mathrm{hr}$ ) and Surti (av. $45.6 \mathrm{hr}$ ) buffalo bull semen. Mixed samples of semen from both buffalo breeds had a keeping quality which was intermediate between those of the two breeds (av. $47.6 \mathrm{hr}$ ). The combination of Murrah buffalo spermatozoa with Zebu bull seminal plasma had the longest keeping quality (64.1 hr). No clumping or agglutination of spermatozoa in the heterospermic or the heteroplasmic treatments was observed at $5 \pm 1{ }^{\circ} \mathrm{C}$ until +3 motility was reached, indicating that selected heteroplasmy plays an important rôle in the maintenance of sperm viability and motility. Heteroplasmic samples showed a superior conception rate $(68 \%)$ over control samples extended with egg-yolk citrate $(44 \%)$.
\end{abstract}

\section{INTRODUCTION}

Any modification or innovation connected with natural or artificial extenders of semen which enhances the longevity and viability of spermatozoa, especially of the buffalo species, would greatly help to improve production of the species.

Williams (1932) reported a relationship between the motility of spermatozoa in stored semen with fertility. Herman \& Swanson (1941) studied the duration of sperm motility of undiluted semen at ' 2 ' $(0$, no motility; 5 , the best initial motility) as a criterion for judging the keeping quality. The semen from many bulls of good fertility was found to average less than $56 \mathrm{hr}$ maintenance of ' 2 ' motility; according to these workers, semen from bulls of good fertility should maintain a high percentage of vigorous motility for at least $30 \mathrm{hr}$ in storage undiluted at $40^{\circ} \mathrm{F}$, and semen which maintained good motility for an average of less than $24 \mathrm{hr}$ was of poor fertility.

Kushner (1954) claimed that mixed semen from different bulls improved the conception rate and produced better offspring. He used both intraspecific and interbreed mixtures for 'heterospermic inseminations'. This claim was supported to some extent by Hess, Ludwick, Rickard \& Ely (1954), but Campbell \& Jaffe (1958) could not confirm their findings. Frappell \& Williams (1956) found no 
improvement in the conception rate when using mixtures of semen samples 4 days after collection, although there was a possible effect of mixing on sperm survival.

Chang (1949) has reported that the seminal plasma as a medium for artificial insemination is beneficial to both motility and fertility. Napier (1961) has noted that the fertility of semen is influenced by the inherent quality of spermatozoa, the composition of the seminal fluid and the interaction of spermatozoa and seminal fluid. Rozin (1961) mentioned that in certain species a relationship has been claimed between certain properties of the seminal plasma and male fertility. Olbrychtowa \& Walkowski (1959) noticed no unfavourable effect on motility and even a beneficial one when bull spermatozoa were suspended in stallion seminal plasma.

The present investigation indicates the effect of heteroplasmy on the motility and viability of spermatozoa in undiluted semen. The undiluted semen mentioned here differs from the homogeneous undiluted semen of a single ejaculate or even from the composite of several ejaculates of the single individual as it is a mixed semen of interbreed (e.g. Bos indicus (Zebu) and Bos taurus) or interspecific nature (e.g. Bubalus bubalis and Bos taurus or Bos indicus). Heteroplasmy refers to a condition in which the spermatozoa of one breed or species are mixed with the seminal plasma of another breed or species.

\section{MATERIALS AND METHODS}

Three Murrah breed buffalo bulls (B9, 638 and SVR), two Surti breed buffalo bulls ( 654 and DC) and two Red Sindhi cattle bulls (250 and 322) maintained by the Central Artificial Insemination Section (CAIS) of the National Dairy Research Institute, Bangalore (India), were used for the present investigation. The bulls were of the same age group, were maintained on a similar feeding schedule, were healthy and had a normal appetite and libido.

Semen was collected with an artificial vagina twice a week (Tuesday and Thursday) using a teaser cow which was not in oestrus (Walton, 1945). Each bull was allowed one false mount before ejaculation into the artificial vagina. The semen that was collected from selected bulls of the same breed was pooled and the volume, colour, consistency, mass activity and motility were recorded. No ejaculate had a volume of less than $3.5 \mathrm{ml}$. The semen was white or creamy white in colour and thick in consistency and showed vigorous mass activity with rapid wave motion.

Sperm motility was evaluated according to the procedure described by Tomar (1970). A drop of semen was spread uniformly over a clean dry glassslide maintained at $37^{\circ} \mathrm{C}$. A hanging-drop microslide with a cavity of $20 \mathrm{~mm}$ in diameter and $0.5 \mathrm{~mm}$ in depth was suitable for examining mass activity of spermatozoa, with a low power microscope. On the basis of the swirling activity, semen was graded into five categories: (i) +5 motility: rapid swirls and waves; 80 to $100 \%$ of spermatozoa are progressively motile; (ii) +4 motility: less rapid swirls and eddies; 60 to $80 \%$ of spermatozoa are progressively motile; (iii) +3 motility: the swirls are slow and scattered in the field; 40 to $60 \%$ of spermatozoa are progressively motile; (iv) +2 motility: 
swirls are absent; individual movements of spermatozoa are more evident in the field; not more than $40 \%$ of spermatozoa are in progressive motion, other spermatozoa show poor motility with oscillating, undulating or circular movements; the non-progressive movement may also be characterized as 'throbbing movement'; $(\mathrm{v})+1$ motility: no wave motion observed; only about $20 \%$ of spermatozoa may have progressive movement; (vi) 0 motility: the spermatozoa are immotile.

The initial motility was further sub-divided into $+5,+4 \cdot 5,+4,+3 \cdot 5,+3$, $+2 \cdot 5,+2,+1 \cdot 5,+1$ and $+0 \cdot 5$ grades. Semen samples with $+2 \cdot 5$, equivalent to approximately $50 \%$ and lower motility rates, were rejected.

The experimental procedures detailed below were followed.

A $3.5-\mathrm{ml}$ quantity of semen was removed from each of the pooled semen samples of each breed: (1) Murrah breed buffalo semen (undiluted); (2) Surti breed buffalo semen (undiluted); (3) Red Sindhi cattle semen (undiluted). The samples were placed in three clean, sterilized, stoppered glass-tubes marked with Treatment numbers 1 to 3 (Table 1).

A 2-ml volume of semen was removed from each of the pooled semen samples of the two breeds of buffalo bulls: (4) Murrah breed buffalo semen + Surti breed buffalo semen (heterospermic mixture). The samples were placed in a clean, sterilized, stoppered glass-tube, mixed and marked with Treatment number 4 (Table 1).

A 6-ml quantity of semen from each pool was centrifuged at $2000 \mathrm{~g}$ for 20 to $25 \mathrm{~min}$. The 'sperm-free' seminal plasma of each of the centrifuged samples was then transferred into other clean, sterilized glass-tubes and heteroplasmic intermixtures were prepared by adjusting the number of spermatozoa to between 8 and $10 \times 10^{6} / \mathrm{ml}$. The samples were allotted treatment numbers (Table 1) as follows: (5) $M B \mathrm{~S} / R S \mathrm{P}$ (Murrah breed of buffalo spermatozoa in Red Sindhi cattle seminal plasma); (6) $R S \mathrm{~S} / M B \mathrm{P}$ (Red Sindhi cattle spermatozoa in Murrah breed of buffalo seminal plasma); (7) $S B$ S/RS P (Surti breed of buffalo spermatozoa in Red Sindhi cattle seminal plasma); (8) RS S/SB P (Red Sindhi bull spermatozoa in Surti breed of buffalo seminal plasma).

Immediately after treatment, the samples were examined under a microscope $(\times 15)$ to check for the presence of an initial sperm motility of +4 . This was confirmed by the technical staff of the CAIS of the Institute, who examined coded samples to achieve unbiased results. The samples were slowly cooled to $5 \pm 1^{\circ} \mathrm{C}$ over $1 \mathrm{hr}$ and were stored at that temperature. The motility of the samples was subsequently evaluated by the same procedure at $4-$ and $12-\mathrm{hr}$ intervals till the motility was assessed at +3 .

To examine the validity of the relationship between sperm motility and fertility (Mann, 1964), field trials involving the artificial insemination of buffaloes in oestrus were conducted for a period of 3 months and the conception rate on a 120-day non-return basis was recorded. Eighty-one 'experimental' buffaloes in oestrus were inseminated with interspecific heteroplasmic spermatozoa treated as in (5), and 110 'control' buffaloes in oestrus were inseminated with the semen from the same bulls extended with egg-yolk-citrate. The artificial inseminations were performed by the staff of the Key Village Unit of the Institute. 


\section{RESULTS}

\section{Undiluted semen}

The data presented in Table 1 show that the undiluted semen samples of the buffalo and Zebu breeds stored at $5 \pm 1^{\circ} \mathrm{C}$ retained their motility up to +3 for the following periods: (1) Murrah semen for a period of 48 to $56 \mathrm{hr}$, with an

Table 1. Keeping quality at $5 \pm 1^{\circ} \mathrm{C}$ of pooled undiluted semen and of other treated semen samples from buffalo bulls (Murrah and Surti) and Zebu bulls (Red Sindhi)

\begin{tabular}{|c|c|c|c|c|c|c|c|c|}
\hline \multirow[b]{2}{*}{ Sample no. } & \multicolumn{8}{|c|}{ Treatment } \\
\hline & 1 & 2 & 3 & 4 & 5 & 6 & 7 & 8 \\
\hline 1 & 48 & 36 & 28 & 48 & 71 & 24 & 48 & 24 \\
\hline 2 & 56 & 48 & 36 & 48 & 72 & 24 & 48 & 24 \\
\hline 3 & 48 & 36 & 32 & 48 & $7 \overline{2}$ & 24 & 48 & 24 \\
\hline 4 & 48 & 48 & 24 & 48 & 60 & 24 & 48 & 24 \\
\hline 5 & 48 & 48 & 28 & 48 & 72 & 24 & 48 & 28 \\
\hline 6 & 52 & 48 & 32 & 48 & 60 & 28 & 48 & 24 \\
\hline 7 & 48 & 48 & 32 & 48 & 60 & 24 & 48 & 24 \\
\hline 8 & 48 & 48 & 32 & 56 & 56 & 28 & 52 & 28 \\
\hline 9 & 52 & 48 & 36 & 48 & 72 & 24 & 48 & 24 \\
\hline 10 & 48 & 36 & 28 & 36 & 56 & 24 & 48 & 28 \\
\hline 11 & 48 & 36 & 32 & 48 & 60 & 24 & 52 & 24 \\
\hline 12 & 48 & 48 & 32 & 48 & 72 & 28 & 48 & 24 \\
\hline 13 & 48 & 48 & 32 & 48 & 56 & 24 & 48 & 28 \\
\hline 14 & 48 & 48 & 32 & 56 & 56 & 24 & 52 & 34 \\
\hline 15 & 52 & 48 & 32 & 48 & 60 & 24 & 48 & 24 \\
\hline 16 & 48 & 48 & 32 & 48 & 60 & 24 & 52 & 24 \\
\hline 17 & 52 & 48 & 28 & 48 & 60 & 24 & 48 & 24 \\
\hline 18 & 52 & 48 & 24 & 36 & 60 & 24 & 48 & 24 \\
\hline 19 & 48 & 36 & 28 & 48 & 72 & 28 & 48 & 28 \\
\hline 20 & 48 & 48 & 28 & 48 & 60 & 24 & 48 & 28 \\
\hline 21 & 52 & 48 & 28 & 48 & 60 & 24 & 48 & 24 \\
\hline 22 & 48 & 48 & 28 & 48 & 72 & 24 & 48 & 24 \\
\hline 23 & 48 & 48 & 28 & 48 & 60 & 28 & 52 & 24 \\
\hline 24 & 52 & 48 & 28 & 48 & 72 & 24 & 48 & 24 \\
\hline 25 & 56 & 48 & 28 & 48 & 72 & 24 & 52 & 24 \\
\hline Total & 1244 & 1140 & 812 & 1192 & 1604 & 620 & 1224 & 624 \\
\hline Average & $49 \cdot 7$ & $45 \cdot 6$ & $32 \cdot 4$ & $47 \cdot 6$ & $64 \cdot 1$ & $24 \cdot 8$ & 48.9 & 24.9 \\
\hline & 48 to 56 & & & 36 to 56 & & 24 to 28 & 48 to 52 & 24 to 28 \\
\hline
\end{tabular}

For treatments, see text. The keeping quality is measured as the time (in hr) needed for the spermatozoa in the semen samples to reach +3 motility.

average of $49.7 \mathrm{hr}$; (2) Surti semen for a period of 36 to $48 \mathrm{hr}$, with an average of $45.6 \mathrm{hr}$; (3) Red Sindhi semen for a period of 24 to $36 \mathrm{hr}$, with an average of $32 \cdot 4 \mathrm{hr}$.

\section{Interbreed heterospermy}

The interbreed heterospermic semen samples of Murrah and Surti buffalo semen (4) retained motility up to +3 for 36 to $56 \mathrm{hr}$, with an average of $47.6 \mathrm{hr}$, an intermediate value between those for the two buffalo breeds.

\section{Interspecific heteroplasmy}

The heteroplasmic treatments of Murrah buffalo spermatozoa in Red 
Sindhi bovine seminal plasma (5), Red Sindhi bovine spermatozoa in Murrah buffalo seminal plasma (6), Surti buffalo spermatozoa in Red Sindhi cattle seminal plasma (7), and Red Sindhi cattle spermatozoa in Surti buffalo seminal plasma (8) showed retention of motility at +3 for a period of 56 to 72 hr (av. 64.1), 24 to $28 \mathrm{hr}$ (av. 24.8), 48 to $52 \mathrm{hr}$ (av. 48.9) and 24 to $28 \mathrm{hr}$ (av. 24.9), respectively.

\section{Fertility trials with Treatment 5}

On a 120-day non-return basis, fifty-five of the 'experimental' and fiftyeight of the 'control' buffaloes were assumed to have conceived, a conception rate of $68 \%$ for the interspecific heteroplasmic spermatozoa and $44 \%$ for the control spermatozoa.

The data in Table 1 suggest that the duration of motility at +3 of undiluted and treated spermatozoa does not follow a normal distribution and this is substantiated by the data for spermatozoa under Treatment 5 . To ensure that the observed difference was not due to chance alone, the Wald-Wolfowitz run test (Siegel, 1956; Rao, Mitra \& Mathai, 1966), which is a non-parametric test, was applied. The null-hypothesis is that there is no difference between Treatment 5 and other treatments with respect to keeping quality. In order to test whether Treatment 5 was different from Treatment 1 , the data from each group were combined and the values were ranked in order of increasing size. The number of runs in this ordered series was determined. The same procedure was followed in the case of other groups. Table 2 shows the total number of runs in each of the seven combined series.

To determine whether the total number of runs was significant at the $5 \%$ level, normal approximation was used, since the sample sizes were more than twenty. The total number of runs in each group was found to be significant.

\section{Agglutination}

Agglutination of spermatozoa kept at $5 \pm 1^{\circ} \mathrm{C}$ was not observed in any of the interspecific and interbreed mixed semen and heteroplasmic combinations up to the time of reaching +3 motility and the inseminations were carried out well before the spermatozoa reached this stage. The viability of spermatozoa treated in the manner described was confirmed by the satisfactory conception rate of the inseminated females.

\section{DISCUSSION}

According to Mann (1964), sperm agglutination may be of two kinds: chemoagglutination and immunological agglutination. The former was not applicable in our studies. Regarding the possible effect of immunological reactions due to specific antigens, the following observations are pertinent. No antigen-antibody effect in the form of an agglutination reaction was observed in our study on heterospermy and heteroplasmy. Maule (1962) reported that there was no evidence of a clumping effect following the mixing of semen. On this basis, he recommended further investigation of the possible beneficial effect of heterospermic insemination. In our work, this has been extended further to 
heteroplasmic insemination. It seems possible that the buffalo and Zebu bull semen in this study have the same or similar 'lipoprotein like' antigens (Padma, 1968), in which case clumping or agglutination of spermatozoa in different mixtures of semen and heteroplasmic treatments will not take place.

The time taken for sperm motility to reach +3 in the undiluted semen samples in this study is in general agreement with the results of Tomar, Jahari, Misra \& Singh (1966). These authors reported that the Zebu (Hariana breed) and buffalo (Murrah breed) semen in undiluted form in vitro at $5^{\circ} \mathrm{C}$ did not reach +3 motility for an average period of 27.3 and $45.2 \mathrm{hr}$, respectively. The difference in the keeping quality values reported by us and those reported by Tomar et al. (1966) may be due to a climatic factor. The work of Tomar et al. (1966) was carried out in a temperate zone with extremes of climatic conditions whereas our work was conducted under more uniform climatic conditions due to the higher altitude of Bangalore (about $3000 \mathrm{ft}$ above sea level).

The effect of mixing semen samples obtained from Murrah and Surti buffaloes on the duration of sperm motility was similar to that reported by Campbell \& Jaffe (1958) for bovine semen. They observed that the motility in a sample of mixed semen was lower than that of the better of two samples included in the mixture. Dott \& Walton (1958) also noted that the motility rating of mixed samples of bull semen was nearer to that of the least active sample than to the mean of all the samples.

In the heteroplasmic studies, the mixture of Murrah bull spermatozoa with Red Sindhi bull seminal plasma resulted in a better average retention of motility than that of undiluted semen samples from either Red Sindhi or Murrah buffalo bulls. This indicates that selected heteroplasmy may have a marked effect in extending the duration of sperm motility.

Since the total number of runs was found to be significant in each of the seven groups, the superiority of the heteroplasmic treatment (5) over the other heteroplasmic treatments (6,7 and 8), undiluted semen (1,2 and 3) and heterospermic treatment (4) under investigation, is confirmed (Table 2).

Table 2. Results of statistical analysis based on the Wald-Wolfowitz run test

\begin{tabular}{l|ccccccc}
\hline & 5,1 & 5,2 & 5,3 & 5,4 & 5,6 & 5,7 & 5,8 \\
\hline $\begin{array}{l}\text { Total number of } \\
\text { runs in the } \\
\text { combined series }\end{array}$ & 2 & 2 & 2 & 2 & 2 & 2 & 2 \\
\hline
\end{tabular}

Using normal approximation, the corresponding value of standard normal deviate is 6.9 when the total number of runs is 2 . Under the assumption that the hypothesis of no difference is true, the probability of 6.9 is less than 0.0006 . Therefore, the total number of runs in each case is significant.

The explanation for the better maintenance of the motility of Murrah buffalo spermatozoa in a heteroplasmic environment rather than in their own natural environment can only be speculative. Some unknown factor in the Zebu bull seminal plasma may be more conducive to the maintenance of buffalo sperm 
viability than that of the Red Sindhi spermatozoa. Alternatively, a factor in the plasma may be activated by the buffalo spermatozoa and contribute towards their longer keeping quality, or there may be a lack of such a factor in the buffalo seminal plasma. It may also be noted that mixture of Red Sindhi spermatozoa with buffalo seminal plasma gave poorer results than the undiluted Red Sindhi semen if the results of Treatment 6 are compared with those of Treatment 3. In the present study, selective heteroplasmic treatment has not only resulted in superior viability and motility but the spermatozoa have also maintained a satisfactory fertilizing ability as was shown by the conception rate.

\section{AGKNOWLEDGMENTS}

The technical help rendered by the staff of CAIS and Key Village Scheme of the Institute and also the help rendered by Dr K. P. Srinath, Reader in Statistics, Bangalore University, Bangalore, are gratefully acknowledged.

\section{REFERENCES}

Campbell, R. G. \& JAfre, W. P. (1958) The motility of mixed semen. F. agric. Sci., Camb. 50, 64.

Chang, M. G. (1949) Effect of heterologous seminal plasma and sperm cells on fertilizing capacity of rabbit spermatozoa. Proc. Soc. exp. Biol. Med. 70, 32.

Dotт, H. M. \& WaLton, A. (1958) Motility and survival of spermatozoa in mixed semen from different bulls. 7. agric. Sci., Camb. 50, 267.

Frappell, J. P. \& Williams, G. (1956) A study of heterospermic insemination in cattle. Proc. 3rd Int. Congr. Anim. Reprod., Camb. 1956, Sect. 1, 65.

Herman, H. A. \& Swanson, E. W. (1941) Variation in dairy bull semen with respect to its use in artificial insemination. Res. Bull. Mo. agric. Exp. Sta. No. 326, 1.

Hess, E. A., Ludwick, T., Rickard, H. G. \& Ely, F. (1954) Some influence of mixed ejaculates upon bovine fertility. F. Dairy Sci. 37, 649, Abstr.

Kushner, H. F. (1954) Gited by Maule, J. P. (Ed.) (1962), p. 95.

Mann, T. (1964) The Biochemistry of Semen and of the Male Reproductive Tract. Methuen, London.

Maule, J. P. (Ed.) (1962) The Semen of Animals and Artificial Insemination. Technical Communication No. 15 of the Commonwealth Bureau of Animal Breeding and Genetics, Edinburgh, England.

NAPIER, R. A. N. (1961) Fertility in the male rabbit. I. Sensitivity of spermatozoa to handling techniques. F. Reprod. Fert. 2, 246.

OlbRYchtowa, F. \& WALKowSKI, L. (1959) Investigation aimed at increasing sperm viability. Med. Wet. 15, 226.

Padma, M. C. (1968) Some features of the isoantigens of cattle and rabbit spermatozoa. D.Sc. thesis, Mysore University, Mysore.

Rao, D., Mitra, S. K. \& MathaI, A. (1966). Formulae and Tables for Statistical Works, p. 98. Statistical Publishing Society, Galcutta.

Rozin, S. (1961) Cited by Mann, T. (1964), p. 66.

Steget, S. (1956) Non-parametric Statistics for the Behavioral Sciences, pp. 136-144. McGraw-Hill, New York.

Tomar, N. S. (1970) Artificial Insemination and Reproduction of Cattle and Buffaloes. Saroj Prakashan, Allahabad.

Tomar, N. S., Jahari, G. B., Misra, V. S. \& Singh, B. (1966) An in-vitro study of undiluted bovine semen. Ind. vet. F. 43, 340-343.

Walton, A. (1945) $A$ Note on the Technique of Artificial Insemination, p. 32. Holborn Surgical Instrument Co. Ltd, London.

Willuams, W. L. (1932) Cited by Anderson, J. (1945) The Semen of Animals and its Use for Artificial Insemination, p. 4. Technical communication, Imperial Bureau of Animal Breeding and Genetics, Edinburgh, England. 